\title{
Exploring the potential of big data on the health care delivery value chain (CDVC): a preliminary literature and research agenda
}

\author{
William Tibben \\ University of Wollongong \\ wjt@uow.edu.au
}

\author{
Samuel Fosso Wamba \\ Toulouse Business School \\ s.fosso-wamba@tbs-education.fr
}

\begin{abstract}
Big data analytics (BDA) is emerging as a game changer in healthcare. While the practitioner literature has been speculating on the high potential of BDA in transforming the healthcare sector, few rigorous empirical studies have been conducted by scholars to assess the real potential of BDA. Drawing on the health care delivery value chain $(C D V C)$ and an extensive literature review, this exploratory study aims to discuss current peer-reviewed articles dealing with $B D A$ across the CDVC and discuss future research directions.
\end{abstract}

\section{Introduction}

Increasing health care costs has become a critically important public policy challenge around the world [75]. While each country has its own unique history and challenges there are good reasons to explore emerging areas of scholarship that address commonalities such as the need for greater efficiency and efficacy of health care delivery. This paper seeks to build on efforts to assess big data in health care by reviewing research literature for its impact on health care delivery. Understandably, many studies have based their assessments using frameworks that have their origins in extant health care delivery models [36, 44, 69, 73, 79]. In contrast, Porter and Teisburg's care delivery value chain (CDVC) is a framework that aims to re-organize the delivery of health care to improve treatment outcomes and reduce costs [53]. Hence, the use of Porter and Teisburg's CDVC model in this paper to evaluate big data research aims to provide an assessment of the transformative potential of big data to facilitate changes in the way health care is delivered

Porter and Teisburg's care delivery value chain (CDVC) model seeks to radically change the organization of health care delivery [53]. The primary features of their CDVC is to promote better patient focused treatment outcomes while improving efficiencies in the delivery of health care services [26, $31,32,34,52]$. A central feature of Porter and
Teisburg's CDVC relates to information and information technology [53]. Accordingly, one essential and strategic aspect, from their perspective, is recognition of the role that information technology plays in enabling transformations from the silo-ed information environments of the past to integrated systems across the whole health care value chain.

The reliance of health care and allied services on patient data and related health care information coupled to mobile technologies and the Internet of Things (IoT) has contributed to enormous growth in health care information. It is understandable that some consider the potential of big data in health care delivery [60]. Big data is defined in this paper using the 5 V-related dimensions of volume, variety, velocity, veracity and value [19]. What is yet to emerge from this research activity is a meaningful understanding of the relative impacts that big data research is having in promoting improved health outcomes for patients or improving efficiencies relative to health costs. In order to create actionable insights that address big data's contributions to these two issues of efficacy and efficiency in the delivery of health care this paper undertakes a review of relevant literature using Porter and Teisburg's CDVC as an analytical framework.

The rest of this paper is organized as follows: Section 2 further explains the concept of care delivery value chains as outlined by Porter and collaborators. Section 3 defines big data and provides some background to its attributes and its potential health care impacts. Section 4 explains the methodology used for the research. Section 5 presents the results of the literatures review analysis. Section 6 moves on to discuss these results and explore implications for future research.

\section{Health Care Delivery Value Chain}

Porter's and Teisburg's care driven value chain (CDVC) aims to re-orientate traditional health delivery models to focus on providing value to the consumers of health care. The CDVC represents a radical shift in the 
delivery of health care away from supply side models where health care is organized around the needs and wants of doctors, hospitals and associated health care units. In their 2006 monograph, Porter and Teisberg reason that the fee-for-service model rewards health care practitioners for their time and expertise without sufficient regard for optimal treatment of the underlying health condition from a patient and cost perspective. This has led to inefficiencies in the delivery of treatments. Their CDVC is organized on the basis of "integrated practice units" that deliver treatment for specific conditions over a full cycle of care [53 p. 49]. As patients progress through the treatment value chain it becomes possible to focus on delivering each stage of care in more cost effective ways. Thereby costs can be reduced without sacrificing standards of care

The CDVC comprises of ten components (see Figure 1). The integrated treatment cycle begins with monitoring and preventing followed by diagnosing, preparing, intervening, recovering rehabbing and monitoring and managing. Each of these can be divided into individual units of costs that can be monitored. However, from the patient's perspective, this cycle of care should be integrated rather than separated as indicated by the three top layers of informing and engaging, measuring and accessing. This is what delivers value to the patient.

The tenth component of the CDVC deals with knowledge development. This covers a broad range of activities such as physician and nurse training, results management and tracking, process improvements and technology development. For the purposes of this paper, knowledge development has been limited here to technology development. Porter and Teisburg outline a specific role for information technology in promoting the dissemination of results-based information generated in the course of treatment [53]. They argue that such information enables competition to flourish which also places downward pressure on health care costs.

So, it is with these factors in mind that the paper moves on to consider the impact of big data in relation to health care delivery.

\section{Big Data}

The "Gartner's Top 10 Strategic Technology Trends for 2017" recognizes advanced analytics within the Intelligent Apps as one of the ten top strategic technology trends for 2017 that, when fully utilized by firms, will help refine their offers and transform customer experience [51]. Big data analytics (BDA) is considered as a "holistic process to manage, process and analyze 5 Vs (i.e., volume, variety, velocity, veracity and value) in order to create actionable insights for sustained competitive advantage" [19]. BDA recently has received much attention from both practitioners and scholars because of its huge potential in transforming firms across industry to achieve sustained competitive advantage [13].

In healthcare, BDA offers many applications including: better prediction of epidemics, treatment of disease, improvement in the quality of life and prevention of preventable deaths [45]. MacDonald [46] identifies five big data trends in healthcare for 2017.

(i) Value-Based, Patient-Centric Care. This aims to capitalize on technology to improve healthcare quality and coordination by delivering "outcomes [that] are consistent with current professional knowledge" (p. 1), while reducing healthcare costs and avoidable overuse, while providing support for reformed payment structures

(ii) The Healthcare Internet of Things (IoT). Alternatively known as the Industrial Internet, IoT is characterized by a variety of devices that will be used to monitor all types of patient behaviors including: glucose monitors, fetal monitors, electrocardiograms, blood pressure and medicines consumption. This envisages a situation called "management of exceptions" in which the need for direct physician intervention is reduced because patients can followed up by a nurse if an exception occurs.

(iii) Reducing Fraud, Waste, and Abuse. Here, the author argues that BDA "can be a game changer for healthcare fraud" because "predictive modeling" using BDA tools can identify "inaccurate claims in a systematic, repeatable way and generate a " $2200 \%$ return on their big data/advanced technology" investment (p. 1).

(iv) Predictive Analytics to Improve Outcomes: Using predictive modeling of health care records has the potential to lead to early diagnosis and reduced mortality rates. More generally, enhanced "accuracy of diagnosing patient conditions, matching treatments with outcomes, and predicting patients at risk for disease or readmission" (p. 1) leads to better and more efficient health outcomes

(v) Real-time Monitoring of Patients. The generation of personalized health case data enables "more proactive care to ... patients by constantly monitoring patient vital signs".

The areas outlined by MacDonald resonate with recent contributions to the academic literature. For example Kohn et al. cite the potential that big data has for better decision making in health care as well as a greater autonomy for the patient in care management [36]. Shah and Jyotishman similarly identify the potential of big data for better integration of health care data, knowledge-creation with consequent improvements in practice [60]. 


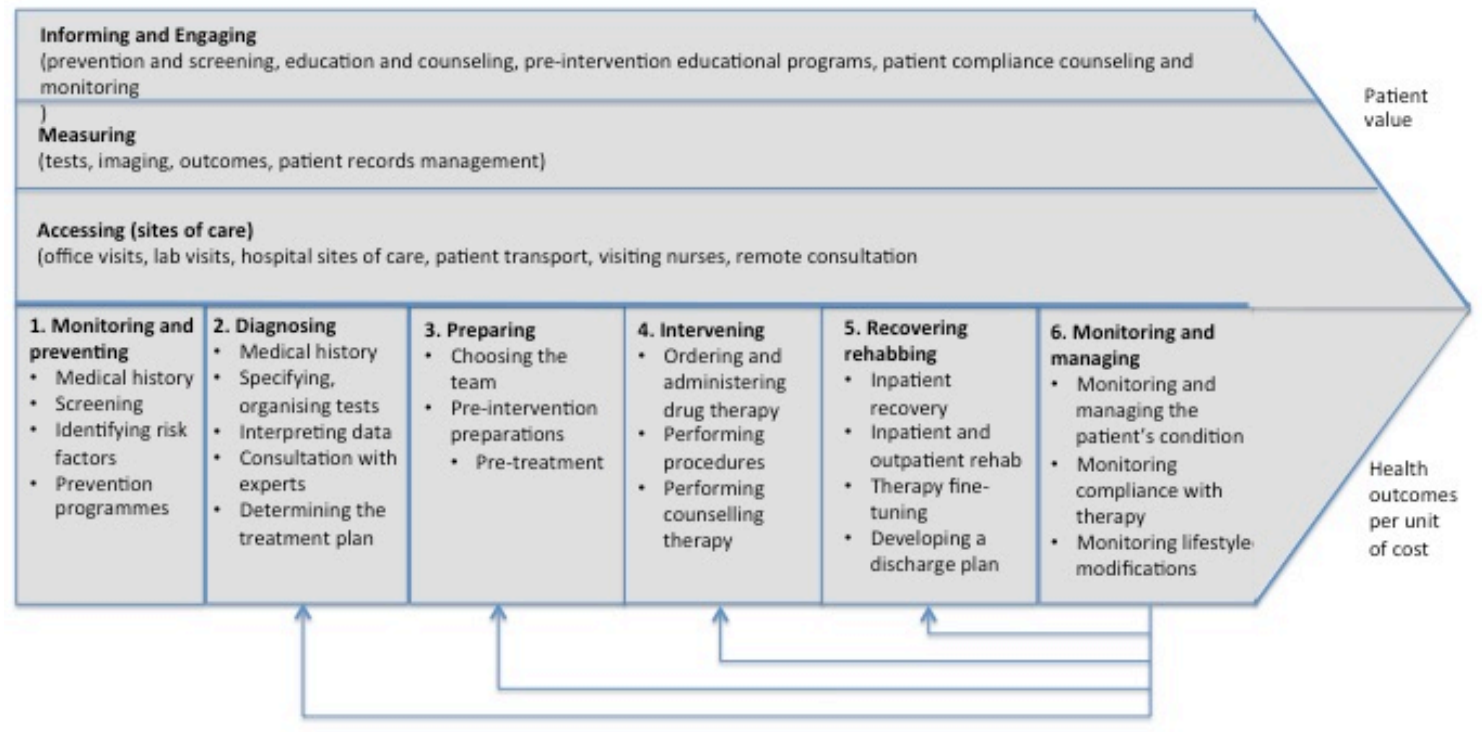

Knowledge

(technology development)

Figure 1 Care Delivery Value Chain Framework (Based on $[34,53])$

Using established frameworks to assess the extant health care-related big data literature enables insights to be developed about relevance of big data research, research gaps and its potential to guide future research. One recent paper uses a framework that draws on the concept of a data life cycle to track data from its capture, transformation to its consumption [73]. This framework emphasizes the role of data governance to support each phase. Another recent paper uses a health care operations and supply chain management (HOSCM) framework to assess the potential of big data research to improve outcomes in health care delivery [44]. The authors found that the HOSCM framework was found wanting in revealing end-to-end care delivery processes thereby not allowing patient pathways to be adequately captured.

The extent to which these apparent failings are a product of the traditionally silo-ed information environments that Porter and his collaborators criticize warrants attention. The application of the CDVC provides an opportunity to assess the potential of big data research to transform health care delivery by focusing on patient value as well as unit health care cost outcomes (see Figure 1). As a consequence the objective of this review is summarized as: find how big data and associated analytics contribute to the delivery of healthcare with an emphasis on Porter and Teisburg's health care delivery value chain (CVDC).

The paper proceeds to outline the steps that were taken to assess current literature in relation to CDVC.

\section{Methodology}

The methods that were adopted in this paper enables an assessment to made of big data research activity in health care delivery and to identify areas for future research. The review of the literature was guided by a protocol adapted from Fosso Wamba et al. [19, 20], Lim et al. [41] and Ngai et al. [49]. The protocol consists of three phases: (i) creation of classification framework; (ii) identification of relevant literature; and (iii) application of classification framework to the literature. The selected literature is limited to peerreviewed journal articles, articles-in-press and reviews are reasoned to be the principal medium by which academic and practitioners obtain and disseminate new information [50].

\subsection{Classification Framework}

The framework used to classify papers is based on Porter CDVC as detailed in Figure 1 [53, 34]. The CDVC is made up of ten categories. Nine of the 
categories (Informing and Engaging, Measuring; Accessing; Monitoring and Preventing; Diagnosing; Preparing; Diagnosing; Recovering Rehabbing and Monitoring Managing) were used to classify the selected literature.

Finally, each paper was considered for the area of technology that was being advanced by the research. Technology in this sense is defined as areas of technical knowledge rather than referring more generally to technical artifacts as evidenced in popular usage of the term (see discussion in [42]).

\subsection{Literature search strategies}

In order to capture the most recent and relevant research a keyword search from the past five years (2012 to 2017) on the SCOPUS database was undertaken. The SCOPUS database is considered an appropriate choice to begin the literature search because it is the largest abstract and citation database of peer-reviewed literature holding more than 19,000 peer-reviewed journals. Only articles, reports and articles-in-press were retained for further analysis

The keywords were derived from the research statement to "find how big data and associated analytics contribute to the delivery of healthcare with an emphasis on Porter and Teisburg's health care delivery value chain (CDVC)." The following keywords were derived: "big data" "business analytics", "analytics", "healthcare" and "care delivery value chain" (including variants: "healthcare delivery value chain", "health care delivery value chain" and "CDVC"). The SCOPUS search is defined by the following: KEY ("Big data" OR "business analytics" OR "analytics" AND "healthcare") AND PUBYEAR $>2012$ ) OR (KEY ("Big data" OR "business analytics" OR "analytics" AND "health care delivery value chain") AND PUBYEAR > 2012 ) OR (KEY ("Big data" OR "business analytics" OR "analytics" AND "healthcare delivery value chain") AND PUBYEAR > 2012 ) OR (KEY ("Big data" OR "business analytics" OR "analytics" AND "CDVC" ) AND PUBYEAR > 2012) OR (KEY ("Big data" OR "business analytics" OR "analytics" AND "care delivery value chain") AND PUBYEAR > 2012) AND (LIMIT-TO (DOCTYPE , "ar") OR LIMIT-TO (DOCTYPE , "re") OR LIMIT-TO (DOCTYPE, "ip")).

Our search started on April 27, 2017 and ended on June 13, 2017. The initial search resulted in 134 articles. One paper was discovered to be redacted so was immediately eliminated from the analysis. The references for the 133 papers, including the abstracts of all articles, were downloaded into Endnote, a reference management software package. Groups were created to categorize articles in the following fashion: 1. Nine papers removed after abstract review by one author because paper did not address either health care delivery or big data as defined by [19]; and 2. 65 papers were removed after a review of full content by both authors to ensure that articles addressed both big data and health care delivery. At the end of this process 59 articles were deemed suitable for our research objectives and were selected for classification.

Further scrutiny of the remaining 59 articles was able to separate some articles on the basis of their research approach. Seventeen articles were found to be literature articles that did not report on research findings beyond the outcome of their analysis of articles. With the elimination of these the final number of articles that were deemed suitable for classification against the CDVC totaled 42 (see Table 1).

\section{Results}

In this section, the results of the review of past literature that intersects both big data and the CDVC delivery will be outlined.

\subsection{Distribution of articles by publication date}

The distribution of articles for the past five years is shown in Figure 2. It can be seen that there is a clear upward trend in the numbers of articles being published. For 2012 only one article was retrieved with only a small increase in 2013. At the time of writing with approximately six months till years-end, the 2017 total had already exceeded the 2016 total of 25 .

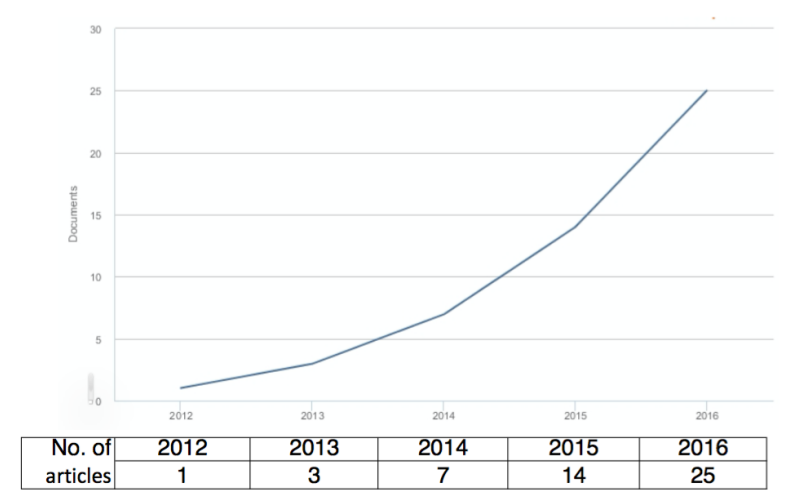

Figure 2 Distribution of articles by year of publication

\subsection{Distribution of articles by CDVC framework}

The allocation of research articles according to the CDVC classification framework (see Figure 1) is summarized in Table 2, 3 and 4. In Table 2 articles 
Table 1. Articles selected for review and classification

\begin{tabular}{ll}
\hline Review articles & [5], [11], [14], [22], [23], [28], [36], [39], [44] [55] [56] [61] [62] [67] [69] [73] [79] \\
\hline Research articles & {$[1],[2][3][4][6][7][8][9][10][12][15][16][17][18][21][24][25][27][29][30][33]$,} \\
& [35] [37] [38] [40] [43] [54] [57] [58] [59] [63] [64] [65] [66] [68] [70] [71] [72] [74] [76], \\
& {$[77][78]$} \\
\hline
\end{tabular}

Table 2. Classification of articles using CDVC framework - patient value

\begin{tabular}{|c|c|c|c|}
\hline CDVC & Article & \# & $\%$ \\
\hline Informing & [1] [2] [3] [8] [9] [16] [21] [24] [29] [40] [43] [59] [63] [65] [66] [76] [77] & 17 & $24 \%$ \\
\hline Measuring & $\begin{array}{l}{[1][3][4][6][7][8][9][10][12][17][18][25][27][29][30][33][35][37][38]} \\
{[40][43][54][57][58][63][64][71][72][74][76][78]}\end{array}$ & 31 & $46 \%$ \\
\hline Accessing & $\begin{array}{l}{[2][4][8][9][10][12][16][17][24][29][37][38][40][43][54][57][64][66]} \\
{[68][72][76][78]}\end{array}$ & 22 & $30 \%$ \\
\hline Total & & 70 & $100 \%$ \\
\hline
\end{tabular}

Note: Some articles counted more than once because they cover more than one element of the CDVC

Table 3. Classification of articles using CDVC framework - treatment cycle

\begin{tabular}{|c|c|c|c|}
\hline CDVC & Article & \# & $\%$ \\
\hline Monitoring and preventing & $\begin{array}{l}{[1][8][9][10][16][18][21][24][29][35][38][40][43][57][71][72][59]} \\
{[58]}\end{array}$ & 18 & $33 \%$ \\
\hline Diagnosing & {$[1][6][12][15][16][18][21][25][27][37][38][54][57][58][70][78]$} & 16 & $30 \%$ \\
\hline Preparing & {$[2][4][15]$} & 3 & $6 \%$ \\
\hline Intervening & {$[2][54][59][64][70]$} & 5 & $9 \%$ \\
\hline Recovering rehabbing & {$[3][7][54][64][70]$} & 5 & $9 \%$ \\
\hline Monitoring and managing & {$[10][29][35][40][43][68][59]$} & 7 & $13 \%$ \\
\hline Total & & 54 & $100 \%$ \\
\hline
\end{tabular}

Note: Some articles counted more than once because they cover more than one element of the CDVC

Table 4. Big data technology development

\begin{tabular}{|c|c|c|c|}
\hline Technology focus & Article & \# & $\%$ \\
\hline Analytics & [1]) [3] [4] [7] [17] [18] [25] [29] [33] [43] [57] [63] [68] [71] [74] & 15 & $36 \%$ \\
\hline $\begin{array}{l}\text { Personalized medicine - IoT \& } \\
\text { Web } 2.0\end{array}$ & {$[2][6][12][24][35][38][40][59][66][76][77]$} & 11 & $26 \%$ \\
\hline $\begin{array}{l}\text { Computer science- processing } \\
\text { large data sets }\end{array}$ & {$[8][10][15][16][21][27][30][58][72][78]$} & 10 & $24 \%$ \\
\hline $\begin{array}{l}\text { Management \& policy (resource } \\
\text { management and ethics) }\end{array}$ & {$[37][54][65][70]$} & 4 & $10 \%$ \\
\hline $\begin{array}{l}\text { User interface design (e.g. data } \\
\text { visualization) }\end{array}$ & [9] [64] & 2 & $5 \%$ \\
\hline Total & & 42 & $100 \%$ \\
\hline
\end{tabular}


were classified by patient value attributes of Informing and Engaging, Measuring and Accessing. It can be seen that the majority of big data articles (31) address the element of Measuring. The allocation of articles to Informing and Engaging and Accessing were 17 and 22 respectively. These three elements are common to all phases of the CDVC and are identified by Porter and his collaborators as providing patient value. All of the reviewed articles can be placed in one of more of these categories so ostensibly provides evidence that the research described by the articles provides added value to patients.

In relation to the CDVC treatment cycle (Table 3 ) it can be seen that the first element of Monitoring and Preventing has attracted the greatest number of articles (18). The second highest treatment area is Diagnosing (16). Interestingly, the areas of Preparing (3) and Intervening (5) were allocated relatively few articles. The final two areas of Recovering Rehabbing (5) and Monitoring and Managing and Policy (7) similarly received relatively small tallies. Hence, it can be seen that the majority of research articles favors the early phases of the CDVC treatment cycle (Monitoring and Preventing and Diagnosing)

In order to develop a deeper understanding of the nature of research that contributes to the CDVC it is useful to review Table 4 which lists areas of technology development represented in each of the articles. From the table it is clear that the largest number of articles describe big data-related innovations in analytics (15). The next most popular area of research concerns personalized medicine where the Internet, Web 2.0, mobile technologies coupled with bio sensors have made a significant impact (11). A similar number of articles pertain to the concerns of computer scientists and the need to process large data sets in a timely manner (10). These papers are notable for being technical in nature (notably Hadoop Mapreduce framework and varying statistical techniques) which use datasets obtained from healthcare applications for their experiments. There are only four papers that deal with relevant management issues such as resource management and ethics. Also connected to Computer Science is user interface design (data visualization) where two studies into data visualization are represented.

Finally, the results of Tables 2-4 are summarized in a CDVC-technology matrix (Table 5). Its possible to gain a sense of the areas in which big data research has been making a greater or lesser impact. In relation to Patient Value, it can be seen that there is a good coverage of technology over the three levels. Notably, Analytics can be seen to be making the greatest impact in the areas of Measuring (14). None of the management papers appear to have informed Accessing sites of care.

Moving on to Health outcomes, Analytics has made the greatest impacts on Monitoring and preventing (6) and Diagnosing (4). Similarly, Computer Science research has a similar concentration in Monitoring and preventing (6) and Diagnosing (6). For Personalized Medicine technologies the greatest areas of impact are Diagnosing (3) and Monitoring and Managing (3). The relatively few papers in Management and Policy made the greatest tallies in Intervening (3) and Recovering and rehabbing (3). User Design papers were evident in Monitoring and preventing (1) Intervening (1) and Recovering and rehabbing (1).

\section{Discussion}

The results summarized in Tables 1-4 begin to provide an insight into the potential impact of big data research to alter the CDVC for healthcare. Each of the areas of the CDVC were relevant to the articles reviewed though its clear that some aspects of the CVDC (Preparing, Intervening, Recovering and Rehabbing) have attracted relatively few articles when compared to other areas (Monitoring and Preventing and Diagnosing).

It is in the treatment cycle element of Preparing which has received the least attention from big data researchers (3). Preparing is defined in the CDVC framework as being made up of "Choosing the team", and "Pre-intervention preparations" (including Pretreatments). One can speculate that the lack of research interest may reflect silo-ed arrangements of care where treatment centers have largely determined the composition of teams and treatments without much consumer input.

There are three areas of technology research from Table 4 represented here: Analytics (design of patient care homes using outpatient data); Personalized Medicine (twitter initiative organizing blood donations in India) and Computer Science data processing (determining optimal chemotherapy treatments from a health records data set).

Moving on to Intervening in Table 3 a slightly higher number of research articles (5) can be found which are diverse in their foci. Intervening is comprised of: "Ordering and administering drug therapy", "Performing procedures" and "Performing counseling therapy". Four of the research articles that have been assigned are: once again, twitter initiative for blood donations; limitations of EU health policy to support personal medicine interventions; user interface design (sepsis management using data visualization); and management (US Medicare cost comparisons for 
Table 5. CDVC - technology matrix

\begin{tabular}{|c|c|c|c|c|c|}
\hline CDVC elements & Analytics & $\begin{array}{l}\text { Personalized } \\
\text { medicine }\end{array}$ & $\begin{array}{l}\text { Computer } \\
\text { science }\end{array}$ & $\begin{array}{l}\text { Management \& } \\
\text { Policy }\end{array}$ & User design \\
\hline \multicolumn{6}{|l|}{ Patient value } \\
\hline Informing & 5 & 7 & 3 & 1 & 1 \\
\hline Measuring & 14 & 6 & 7 & 2 & 2 \\
\hline Accessing & 3 & 4 & 5 & 0 & 1 \\
\hline \multicolumn{6}{|l|}{ Health outcomes } \\
\hline Monitoring and preventing & 6 & 0 & 6 & 0 & 1 \\
\hline Diagnosing & 4 & 3 & 6 & 1 & 0 \\
\hline Preparing & 1 & 1 & 1 & 0 & 0 \\
\hline Intervening & 0 & 1 & 0 & 3 & 1 \\
\hline Recovering rehabbing & 2 & 0 & 0 & 3 & 1 \\
\hline Monitoring and managing & 3 & 3 & 1 & 0 & 0 \\
\hline
\end{tabular}

interventions across the US). The fifth article discusses the potential of combining big data analytics with virtual physiological human (PVH) technology in treatments of disease research. The technology mix from this category as revealed in Table 5 indicates that one study is assigned to personalized medicine (twitter), three papers to Management and Policy (US Medicare cost comparisons, EU health policy for personalized medicine and PVH research policy) and one to User Design.

Recovering Rehabbing in Table 3 indicates a similarly low tally of big data articles with five papers assigned. Recovering Rehabbing entails the following: "Inpatient recovery", "Inpatient and outpatient rehab", "Therapy fine- tuning" and "Developing a discharge plan". Looking to Table 5, the five papers assigned are comprised of two from analytics researchers (re-admissions), two from Management and Policy (EU health policy for personalized medicine and cost comparisons across the US for readmissions) and one from data visualization (dash boards for sepsis management).

The final treatment element considered in Table 3 is Monitoring and Managing. Analytics (e.g. predicting readmissions monitoring after effects of health shocks) and personalized medicine (e.g. bio sensing, smart home monitoring) from Table 4 are most strongly represented here. The CVDCtechnology matrix (Table 5) indicates that three papers are drawn from analytics, three from personalized medicine and one from Computer Science. One can see a similarity in these research articles with those performed in the Monitoring and preventing stage. Opportunities to engage with community members before or after their treatment within health facilities seems to be better than that once patients enter such facilities.

Broadly summarizing, it can be seen that there is a strong representation of papers that engage with patients before entry into and after treatment regimes within health care facilities. Much less engagement can be seen with health care delivery around Intervening and Recovering Rehabbing suggesting the need for more attention to these areas if big data is to facilitate changes to all aspects of the CDVC. The relatively small number of big data articles that deal with Management and Policy can similarly be seen as a future research need to address questions of efficiency within the CDVC.

To that end, a need for greater engagement of big data researchers with treatment (Preparing, Intervening and Recovering Rehabbing) is one future area of research the paper suggests. Another area is the need for big data researchers to engage with management and policy issues of CVDC. The case for change to CVDCs is likely to be met with resistance from entrenched interests. According to Porter and his collaborators, the tendency to replicate existing models of health care privileges the interests of health and allied care practitioners over patient value and lowering costs. The need for robust evidence to agitate for such change outlines a significant research challenge of big data researchers.

The findings from this paper have limitations in that the selection of literature was from one database. Further work in this area should initially seek to broaden the literature base to confirm the initial findings from this analysis. 


\section{Conclusion}

This paper seeks to provide an informed understanding of the impact of big data research on health care delivery. Using the care delivery value chain (CDVC) framework developed by Porter and collaborators it has been possible to see what aspects of health care delivery have benefitted most from big data research and areas that have been given less attention. Health care delivery involves many different disciplines none more so than medical and allied health professions. However, there is a critically important role for IS scholarship too as demonstrated through the examples outlined in relation to CDVC. While there is an ongoing role for big data research to address improvements in treatments the paper finds that there is a greater need for increased attention to management and policy development that aims to promote more personalized modes of care that create increased patient value while simultaneously seeking to achieve greater efficiencies in the delivery of health care.

\section{References}

[1] A. Abbas, M. Ali, M. U. Shahid Khan and S. U. Khan, "Personalized healthcare cloud services for disease risk assessment and wellness management using social media", Pervasive and Mobile Computing, 28 (2016), pp. 81-99.

[2] R. A. Abbasi, O. Maqbool, M. Mushtaq, N. R. Aljohani, A. Daud, J. S. Alowibdi and B. Shahzad, "Saving lives using social media: Analysis of the role of twitter for personal blood donation requests and dissemination", Telematics and Informatics (2017).

[3] S. E. Abdelrahman, M. Zhang, B. E. Bray and K. Kawamoto, "A three-step approach for the derivation and validation of high-performing predictive models using an operational dataset: Congestive heart failure readmission case study", BMC Medical Informatics and Decision Making, 14 (2014).

[4] S. Ajorlou, I. Shams and K. Yang, "An analytics approach to designing patient centered medical homes", Health Care Management Science, 18 (2015), pp. 3-18.

[5] A. Asante-Korang and J. P. Jacobs, "Big Data and paediatric cardiovascular disease in the era of transparency in healthcare", Cardiology in the Young, 26 (2016), pp. 1597-1602.

[6] G. Atluri, A. Macdonald, III, K. O. Lim and V. Kumar, "The Brain-Network Paradigm: Using Functional Imaging Data to Study How the Brain Works", Computer, 49 (2016), pp. 65-71.

[7] I. Bardhan, J. H. Oh, Z. Zheng and K. Kirksey, "Predictive analytics for readmission of patients with congestive heart failure", Information Systems Research, 26 (2015), pp. 19-39.

[8] F. A. Batarseh and E. A. Latif, "Assessing the Quality of Service Using Big Data Analytics: With Application to Healthcare", Big Data Research, 4 (2016), pp. 13-24.
[9] P. Calyam, A. Mishra, R. B. Antequera, D. Chemodanov, A. Berryman, K. Zhu, C. Abbott and M. Skubic, "Synchronous Big Data analytics for personalized and remote physical therapy", Pervasive and Mobile Computing, 28 (2016), pp. 3-20.

[10] H. Chen and Z. Fu, "Hadoop-Based Healthcare Information System Design and Wireless Security Communication Implementation", Mobile Information Systems, 2015 (2015).

[11] A. Chluski and L. Ziora, "The application of mobile technology management concept and big data solutions in healthcare", Polish Journal of Management Studies, 12 (2015), pp. 37-47.

[12] G. Csepeli and R. Nagyfi, "Facebook diagnostics: Detection of mental health problems based on online traces", European Journal of Mental Health, 9 (2014), pp. 220-230.

[13] T. H. Davenport and J. G. Harris, Competing on analytics: the new science of winning, Harvard Business School Press, Boston, Massachusetts, 2007.

[14] R. R. Dewangan, D. Thombre and C. Patel, "Big data technology in health and biomedical research: A literature review", International Journal of Database Theory and Application, 9 (2016), pp. 175-184.

[15] E. Elsebakhi, F. Lee, E. Schendel, A. Haque, N. Kathireason, T. Pathare, N. Syed and R. Al-Ali, "Largescale machine learning based on functional networks for biomedical big data with high performance computing platforms", Journal of Computational Science, 11 (2015), pp. $69-81$.

[16] K. Feldman, D. Davis and N. V. Chawla, "Scaling and contextualizing personalized healthcare: A case study of disease prediction algorithm integration", Journal of Biomedical Informatics, 57 (2015), pp. 377-385.

[17] S. Feuerriegel, "Decision support in healthcare: determining provider influence on treatment outcomes with robust risk adjustment", Journal of Decision Systems, 25 (2016), pp. 371-390.

[18] A. R. M. Forkan, I. Khalil, A. Ibaida and Z. T. Member, "BDCaM: Big Data for Context-Aware monitoring-a personalized knowledge discovery framework for assisted healthcare", IEEE Transactions on Cloud Computing, PP (2015).

[19] S. Fosso Wamba, S. Akter, A. Edwards, G. Chopin and D. Gnanzou, "How 'big data' can make big impact: Findings from a systematic review and a longitudinal case study", International Journal of Production Economics, 165 (2015), pp. 234-246.

[20] S. Fosso Wamba, A. Anand and L. Carter, "A literature review of RFID-enabled healthcare applications and issues", International Journal of Information Management, 33 (2103), pp. 875-891.

[21] J. Frizzo-Barker, P. A. Chow-White, A. Charters and D. Ha, "Genomic Big Data and Privacy: Challenges and Opportunities for Precision Medicine", Computer Supported Cooperative Work: CSCW: An International Journal, 25 (2016), pp. 115-136.

[22] D. Gu, J. Li, X. Li and C. Liang, "Visualizing the knowledge structure and evolution of big data research in healthcare informatics", International Journal of Medical Informatics, 98 (2017), pp. 22-32. 
[23] K. Y. He, D. Ge and M. M. He, "Big data analytics for genomic medicine", International Journal of Molecular Sciences, 18 (2017).

[24] C. Heavin and Y. O'Connor, "Starting with small health data opportunities for Mhealth in Africa", International Journal of Design and Nature and Ecodynamics, 11 (2016), pp. 338-351.

[25] M. S. Hossain and G. Muhammad, "Healthcare Big Data Voice Pathology Assessment Framework", IEEE Access, 4 (2016), pp. 7806-7815.

[26] A. Ignatius, "Fixing a Broken System", Harvard Business Review, 94 (2016), pp. 8.

[27] S. Istephan and M. R. Siadat, "Unstructured medical image query using big data - An epilepsy case study", Journal of Biomedical Informatics, 59 (2016), pp. 218-226. [28] K. Jee and G. H. Kim, "Potentiality of big data in the medical sector: Focus on how to reshape the healthcare system", Healthcare Informatics Research, 19 (2013), pp. 79-85.

[29] L. Jiang and C. C. Yang, "User recommendation in healthcare social media by assessing user similarity in heterogeneous network", Artificial Intelligence in Medicine (2017).

[30] P. Kalmane and J. S. Kallimani, "An approach for big data analytics on $\log$ data of medical devices in healthcare", International Journal of Applied Engineering Research, 10 (2015), pp. 23923-23932.

[31] R. S. Kaplan and M. E. Porter, "How to Pay for Health Care", Harvard Business Review, 94 (2016), pp. 88-100.

[32] R. S. Kaplan and M. E. Porter, "How to Solve the Cost Crisis in Health Care", Harvard Business Review, 89 (2011), pp. 46-64.

[33] K. Kaur and R. Rani, "A Smart Polyglot Solution for Big Data in Healthcare", IT Professional, 17 (2015), pp. 4855.

[34] J. Y. Kim, P. Farmer and M. E. Porter, "Redefining global health-care delivery", The Lancet, 382 (2013), pp. 1060-1069.

[35] T. W. Kim and J. H. Seu, "Big data framework for uHealthcare system", Life Science Journal, 11 (2014), pp. 112-116.

[36] M. S. Kohn, J. Sun, S. Knoop, A. Shabo, B. Carmeli, D. Sow, T. Syed-Mahmood and W. Rapp, "IBM's Health Analytics and Clinical Decision Support", Yearbook of medical informatics, 9 (2014), pp. 154-162.

[37] E. Körpeoğlu, Z. Kurtz, F. Kilinç-Karzan, S. Kekre and P. A. Basu, "Business analytics assists transitioning traditional medicine to telemedicine at virtual radiologic", Interfaces, 44 (2014), pp. 393-409.

[38] H. J. La, "A conceptual framework for trajectorybased medical analytics with IoT contexts", Journal of Computer and System Sciences, 82 (2016), pp. 610-626.

[39] G. Z. Li and B. Y. Liu, "Big data is essential for further development of integrative medicine", Chinese Journal of Integrative Medicine, 21 (2015), pp. 323-331.

[40] Z. Liao, L. Kong, X. Wang, Y. Zhao, F. Zhou, Z. Liao and $X$. Fan, "A visual analytics approach for detecting and understanding anomalous resident behaviors in smart healthcare", Applied Sciences (Switzerland), 7 (2017).

[41] M. K. Lim, W. Bahr and S. C. H. Leung, "RFID in the warehouse: a literature analysis (1995-2010) of its applications, benefits, challenges and future trends", International Journal of Production Economics, 145 (2013), pp. 409-430.

[42] S. Macdonald, Technology beyond machines, in S. Macdonald, D. Lamberton and T. Mandeville, eds., The trouble with technology, Francis Pinter, London, 1983, pp. 26-36.

[43] S. Mahmud, R. Iqbal and F. Doctor, "Cloud enabled data analytics and visualization framework for healthshocks prediction", Future Generation Computer Systems, 65 (2016), pp. 169-181.

[44] M. M. Malik, S. Abdallah and M. Ala'raj, "Data mining and predictive analytics applications for the delivery of healthcare services: a systematic literature review", Annals of Operations Research (2016), pp. 1-26.

[45] B. Marr, How Big Data Is Changing Healthcare, Forbes, 2015.

[46] C. McDonald, 5 Big Data Trends in Healthcare for 2017, MapR, 2017.

[47] E. W. T. Ngai and A. Gunasekaran, "A review for mobile commerce research and applications", Decision Support Systems, 43 (2007), pp. 3-15.

[48] E. W. T. Ngai, Y. Hu, Y. H. Wong, Y. Chen and X. Sun, "The application of data mining techniques in financial fraud detection: a classification framework and an academic review of literature", Decision support systems and electronic commerce 50 (2011), pp. 559-569.

[49] E. W. T. Ngai, J. K. L. Poon, F. F. C. Suk and C. C. $\mathrm{Ng}$, "Design of an RFID-based healthcare management system using an information system design theory", Information Systems Frontiers, 11 (2009), pp. 405-417.

[50] E. W. T. Ngai and F. K. T. Wat, "A literature review and classification of electronic commerce research", Information Management, 39 (2002), pp. 415-429.

[51] K. Panetta, Gartner's Top 10 Strategic Technology Trends for 2017, Gartner, 2016.

[52] M. E. Porter, "What is Value in Health Care?", The New England Journal of Medicine, 363 (2010), pp. 2477 2481.

[53] M. E. Porter and E. O. Teisberg, Redefining Health cCare: Creating Value-based Competition on Results, Harvard Business School Press, Boston, Massachusetts, 2006.

[54] V. Raghupathi and W. Raghupathi, "Exploring cost and quality of medicare in the United States using analytics", International Journal of Healthcare Information Systems and Informatics, 11 (2016), pp. 1-18.

[55] D. Reena, S. Balvinder and K. S. Kumar, "Opportunities and challenges of using Big Data Analytics in Indian healthcare system", Indian Journal of Public Health Research and Development, 7 (2016), pp. 238-243.

[56] J. F. Rodrigues, F. V. Paulovich, M. C. F. De Oliveira and O. N. De Oliveira, "On the convergence of nanotechnology and Big Data analysis for computer-aided diagnosis", Nanomedicine, 11 (2016), pp. 959-982.

[57] P. K. Sahoo, S. K. Mohapatra and S. L. Wu, "Analyzing Healthcare Big Data with Prediction for Future Health Condition", IEEE Access, 4 (2016), pp. 9786-9799.

[58] P. Sampath, S. Tamilselvi, N. M. Saravana Kumar, S. Lavanya and T. Eswari, "Diabetic data analysis in healthcare using Hadoop architecture over big data", 
International Journal of Biomedical Engineering and Technology, 23 (2017), pp. 137-147.

[59] S. Schee Genannt Halfmann, N. Evangelatos, P. Schröder-Bäck and A. Brand, "European healthcare systems readiness to shift from 'one-size fits all' to personalized medicine", Personalized Medicine, 14 (2017), pp. 63-74.

[60] N. D. Shah and P. Jyotishman, Why Health Care May Finally Be Ready for Big Data, Harvard Business Review Digital, Harvard Business Review School Publishing Corp, 2014, pp. 2-5.

[61] V. Shetty and M. Yamaguchi, "Point-of-care testing in the time of P5 medicine: A preface", Sensors and Materials, 28 (2016), pp. 1141-1148.

[62] R. Sreekanth, R. R. Gondkar and R. S. Ravindra Babu, "Cloud computing architecture to process big data healthcare information for health care industries", International Journal of Applied Engineering Research, 9 (2014), pp. 4905-4911.

[63] U. Srinivasan and B. Arunasalam, "Leveraging big data analytics to reduce healthcare costs", IT Professional, 15 (2013), pp. 21-28.

[64] J. G. Stadler, K. Donlon, J. D. Siewert, T. Franken and N. E. Lewis, "Improving the Efficiency and Ease of Healthcare Analysis Through Use of Data Visualization Dashboards", Big Data, 4 (2016), pp. 129-135.

[65] A. Stylianou and M. A. Talias, "Big data in healthcare: a discussion on the big challenges", Health and Technology, 7 (2017), pp. 97-107.

[66] X. Tang and C. C. Yang, "Ranking user influence in healthcare social media", ACM Transactions on Intelligent Systems and Technology, 3 (2012).

[67] L. A. Tawalbeh, R. Mehmood, E. Benkhlifa and H. Song, "Mobile Cloud Computing Model and Big Data Analysis for Healthcare Applications", IEEE Access, 4 (2016), pp. 6171-6180.

[68] K. Topuz, H. Uner, A. Oztekin and M. B. Yildirim, "Predicting pediatric clinic no-shows: a decision analytic framework using elastic net and Bayesian belief network", Annals of Operations Research (2017), pp. 1-21.

[69] C. W. Tsai, M. C. Chiang, A. Ksentini and M. Chen, "Metaheuristic Algorithms for Healthcare: Open Issues and
Challenges", Computers and Electrical Engineering, 53 (2016), pp. 421-434.

[70] M. Viceconti, P. Hunter and R. Hose, "Big Data, Big Knowledge: Big Data for Personalized Healthcare", IEEE Journal of Biomedical and Health Informatics, 19 (2015), pp. 1209-1215.

[71] L. L. Vie, K. N. Griffith, L. M. Scheier, P. B. Lester and M. E. P. Seligman, "The Person-Event Data Environment: Leveraging big data for studies of psychological strengths in soldiers", Frontiers in Psychology, 4 (2013).

[72] F. Wang, "Adaptive semi-supervised recursive tree partitioning: The ART towards large scale patient indexing in personalized healthcare", Journal of Biomedical Informatics, 55 (2015), pp. 41-54.

[73] Y. Wang, L. A. Kung and T. A. Byrd, "Big data analytics: Understanding its capabilities and potential benefits for healthcare organizations", Technological Forecasting and Social Change (2016).

[74] M. J. Ward, K. A. Marsolo and C. M. Froehle, "Applications of business analytics in healthcare", Business Horizons, 57 (2014), pp. 571-582.

[75] World Health Organisation, World Report on Health Policy and Systems Research, World Health Organisation, Switzerland, 2017.

[76] J. Wu, H. Li, S. Cheng and Z. Lin, "The promising future of healthcare services: When big data analytics meets wearable technology", Information and Management, 53 (2016), pp. 1020-1033.

[77] J. Wu, H. Li, L. Liu and H. Zheng, "Adoption of big data and analytics in mobile healthcare market: An economic perspective", Electronic Commerce Research and Applications, 22 (2017), pp. 24-41.

[78] W. Xiang, G. Wang, M. Pickering and Y. Zhang, "Big video data for light-field-based 3D telemedicine", IEEE Network, 30 (2016), pp. 30-38.

[79] J. J. Yang, J. Li, J. Mulder, Y. Wang, S. Chen, H. Wu, Q. Wang and H. Pan, "Emerging information technologies for enhanced healthcare", Computers in Industry, 69 (2015), pp. 3-11. 